\title{
Claims on Sri Lankan Food Labels: A Comparative Legal Analysis with Selected Jurisdictions
}

\section{Charith Amidha Hettiarachch ${ }^{1 *}$, Mahendra Arnold ${ }^{2}$, Niroshika Liyana Muhandiram ${ }^{3}$, Jon Wardle ${ }^{4}$}

1,2Ministry of Health, Sri Lanka

${ }^{3}$ Dept. of Legal Studies, The Open University of Sri Lanka, Sri Lanka

${ }^{4}$ Department of Public Health, University of Technology, Australia

\section{Abstract}

Claims on labels are one of major marketing strategies in the food industry. Health of consumers may be affected by inaccurate and misleading claims and therefore, such claims need to be regulated by state legislation. The Food (Labelling and Advertising) Regulations, 2005 made under the Food Act of 1980 is the main law governing food labelling claims in Sri Lanka.

This study is a desk review which analyses the relevant regulations in the Food (Labelling and Advertising) Regulations, 2005. The study further critiques the existing regulations and compares with international standards (Codex Alimentarius) and regulations in developed countries such as Australia which have a broad local and international food market with modern technology.

The objective of the study is to identify the scope of the 'claim' and its current legislative pitfalls under the existing Sri Lankan legal domain together with its permeability and restrictions.

This study finds that the regulations on claims are not precisely structured and less strong in Sri Lanka. The scope of the definition of 'claim' is vague. Only limited types of claims are stated within the legislation and are often wrongly classified. Certain claim types are not

\footnotetext{
* Corresponding should be addressed to Dr Charith Amidha Hettiarachchi, Ministry of Health, Sri Lanka
}

Email:dr.charith@gmail.com

(D) https://orcid.org/0000-0002-7329-6581

(Received $2^{\text {nd }}$ June 2020; Revised $18^{\text {th }}$ December 2020; Accepted 20th December 2020 (C) OUSL) 
defined at all in the Sri Lankan regulations. Therefore, this study suggests that in order to improve public health, future amendments to the existing regulations are necessary with broader, stronger and clear regulations.

Keywords: Food Label, claim, labelling regulations

\section{Introduction}

\section{Background of the Study}

The general meaning of the word 'claim' is a statement that something is true or is a fact, although the statement alone cannot prove it and people may or may not believe it (Cambridge Dictionary, 2020). A 'claim' can also be a something which someone says which the person making the 'claim' cannot prove and which may be false (Collins Dictionary, 2020).

The Sri Lankan law on food label claims is stipulated in Food (Labelling and Advertising) Regulations of 2005 which is made under the Food Act of 1980. In Sri Lankan law, food labelling regulations define a claim as any representation which states, suggests or implies that a food has a particular quality relating to its origin, nutritional properties, nature processing, composition, or any other quality (Government Publication Bureau, 2005).

Claims are common in food labels. They are a major method by which to deliver a manufacturer's message directly to the consumer. Claims are most important items in a label in terms of food marketing, and often infer a particular quality of the food product. Therefore, it is not surprising that most of items in any given food label are claims. Given their prominence, regulation of claims made on food labels is necessary to protect the health concerns of consumers.

Due to the complexity of laws, it is often not easy to understand whether any particular claim complies with the regulations. Such complexity often confuses manufacturers, authorities, authorized officers and even lawyers. First a claim should be identified and thereafter assessment can be made on its legality.

In this study, the Sri Lankan regulations on food labelling claims were compared with International Food Standards (Codex Alimentarius) and the Australian regulations on food labelling claims. Australia is a developed country where local and international food trade prevail 
with modern technology. The Australian food law is based on Food Standard Code (FSANZ) which is not limited to Australia but also extends to New Zealand.

\section{Scope of the Study}

Provisions on claims in food labels are outlined in section 13 of the Sri Lankan Food (Labelling and Advertising) Regulations, 2005. This study analyses all the relevant sections related to claims, which are mainly focused in section 13 of the Sri Lankan Food (Labelling and Advertising) Regulations, 2005.

\section{Aim of the Study}

The aim of the study is to provide a comprehensive legal analysis of Sri Lankan laws related food labelling claims in order to identify legal pitfalls that need to be corrected.

\section{Justification of the Study}

A claim is the most important 'advertisement' or direct-to-consumer message of food manufacturers in a food label. Therefore, it is perhaps natural that food manufacturers will try to use unjustified or unproven claims in a food label in order to promote their products. This can potentially mislead consumers and ultimately affect human health. As such it is the responsibility of the state to regulate these claims. However, in order to ensure compliance, the labelling regulations should be clear and strong enough to enable such regulatory action. Therefore, a legal review of the existing regulations is important to understand the scope and restrictions in regulations relevant to food claims in Sri Lanka, in order to provide manufacturer, policy and public health stakeholders clarity on the issue.

\section{Theoretical Framework}

The Sri Lankan regulations on food labelling claims were compared with International Food Standards (Codex Alimentarius) and the Australian regulations on food labelling claims to perform a comparative legal analysis.

\section{Review of Literature}

Manufacturers influence consumers to buy their products through a number of mechanisms, one such modality being their food labels. 
Information on food labels could help consumers to make healthy choices. For example, they may facilitate the comparison of the nutritional values of different foods (LaBarbera, 2012). However, manufacturers often use food labels to suggest their products are healthier than they really are (Gunnars, 2016). Although a potential tool for improved health, food labels can also be used to mislead the consumer. If consumers do not have sound knowledge based on which to judge labelling claims, they may not be able to choose healthy food (Jolliffee, 2013). Therefore, sound legislative control on labelling information is necessary to protect consumers' health.

In Sri Lanka, food labelling does appear to influence consumer behaviour. The impact of nutritional labelling on consumer buying behaviour in Kandy, Sri Lanka was assessed. This cross-sectional study selected 90 consumers randomly from three supermarkets, and assessed the consumer's awareness on nutritional labelling and the effect of nutrition labelling on buying. Of the surveyed consumers, $65 \%$ bought products with nutrition labelling due to perceived benefits, suggesting the importance of the implementing appropriate labelling regulations (Prathiraja and Ariyawardana, 2011). A community based cross-sectional study was carried out among grade 12 students in government schools in the Colombo district to assess the snacking behaviour, use of food labels on making choices of packed foods/drinks, and knowledge on food labels and attitude towards media strategies used on food labels. More than $70 \%$ of the students paid attention to information on the label. Majority agreed that the information given on labels of expensive and popular brands to be trustworthy (Thalagala, 2011). These findings suggest that regulating labelling information such as claims will positively influence the purchasing behaviour of consumers.

In an Australian study, Colmar Brunton's Social Research (2007) found that nutrient content claims were present on $85 \%(n=159)$ of the food labels; however, only $20 \%$ of shoppers had read it. The trust towards nutrition content claims was significantly higher for those who reported reading it. 17\% shoppers had bought the product based on perceived healthfulness based on information on the label. The presence of trustworthy claims can lead to improved nutritional decision making and critical assessment of label claims. An experimental study was conducted by TNS Social Research Consultants in 2007 among 1,007 Australian and New Zealand consumers on consumer interpretations of the statement 'no added 
sugar' in food labels, revealed that consumers' awareness on the presence of sugar in 'no added sugar' labels were high. This was presumed to be because a high percentage $(60 \%)$ of consumers had used the nutrition information on the label, which indicated sugar content (FSANZ, 2019). The United States data have shown that consumers rate products with health claims higher than the products without health claims (Roe et al., 1999). Therefore, consumers may inappropriately attribute health benefits to the food product, if claims are not properly regulated by the law. This shows the influence of claims on the food label and the importance of its accuracy towards consumer attitudes.

The impact of legislation does appear to have an effect on claims. Repeated cross-sectional analysis was performed on Canadian consumers to compare the influence of labelling claims between the years 2010 and 2013. It was found that nearly half (49\%) of food labels displayed any type of claim and nearly half out of these $(46 \%)$ were nutrition claims. The percentage of health claims were significantly lower $(p=0.020)$ in $2013(1.5 \%)$ compared to $2010(1.7 \%)$ after introduction of new legislations on claims (Arellano at el., 2017). This proves the success of enacting stringent labelling laws on food labelling claims.

A quasi-experimental study conducted in Sri Lanka reveals that 36.4\% $(n=4)$ of labels with the term 'fortified' food, $50 \%(n=3)$ of labels with the term 'enriched or fortified with vitamin C', 63.65\% $(n=70)$ of labels with the term 'pure' and $80 \%(n=16)$ of labels with the term 'natural' are non-compliant to regulations (Hettiarachchi, 2017). Participants of a focus group discussion in the same study claimed that some labels were clearly incorrect and misled the consumers, with one of the common methods used to mislead the consumer being pictures that are displayed on the label. Participants stated that children were also misled by pictures (Hettiarachchi, 2017). These findings suggest that the implementation of labelling regulations related to food claims is not satisfactory in Sri Lanka. Therefore, the state should take action to review these perceived lapses of existing labelling laws, especially on claims which are used as marketing strategies. 


\section{Methodology}

An extensive literature search was performed to identify national and international sources using multiple strategies. Standards and regulations were searched in the official websites of organizations and departments. Further, theses of doctorate degrees, articles from international and local journals were reviewed. Use of claims by manufacturers and consumers as well as the existing compliance to regulations were studied and sited.

Even though claims contribute significantly to marketing endeavours by food manufacturers, limited regulations exist. Current regulations were analysed based on main three aspects: 1. Identification of a 'claim' 2. Types of claims and 3. How claims are regulated

To provide a global context Codex Labelling Standards and Food Standards of Australia and New Zealand on labelling claims were compared with the Sri Lankan scenario.

\section{Findings and Discussion}

\section{Identification of a 'Claim'}

Section 13.3 (1) of the Regulations defines a claim as any representation which states, suggests or implies that a food has a particular quality relating to its origin, nutritional properties, nature, processing, composition, or any other quality. The term 'particular quality' is not explicitly defined or explained under the Regulations. This is a broad definition and can catch most statements on the label as a 'claim' though, this definition is restricted to section 13 (and thus excludes section 11 and section 12). However, this legal point is not yet argued in the Sri Lankan higher courts.

Section 11 focuses on the recommendations made by medical practitioner, association or professional on the label, which are considered recommendations of third parties rather than claims. Section 12 stipulates that no label (or advertisement) relating to any food shall contain a statement or claim of 'special characteristics' of a food unless approved by the Chief Food Authority. However, notably the term 'special characteristics' is neither defined nor explained in the Regulations. However, this legal point too is not yet argued in the Sri Lankan higher courts. 
The Sri Lankan laws differ slightly from international norms. International Food Standards developed by Codex Alimentarius Commission - a joint programme of Food and Agricultural Organization and World Health Organization - on labelling regulations define a 'claim' as any representation which states, suggests or implies that a food has particular characteristics relating to its origin, nutritional properties, nature, production, processing, composition or any other quality (Codex Alimentarius, 1991). Though the Sri Lankan law has attempted to adopt the same Codex definition in the Regulations - and has largely done so - the word 'production' is missing in the Sri Lankan definition. The words 'production' and 'processing' might be understood as synonyms by the members of the general public, but they have two different meanings. There may be production without processing (for example, the original and natural food can be packed without undergoing any change to the food). In Australia and New Zealand FSANZ defines a 'claim' as an expressed or implied statement, representation, design or information in relation to a food or a property of food. 'Property of food' means a component, ingredient, constituent or other feature of food (FSANZ, 2003). Therefore, the Sri Lankan definition of claim seems to be more restricted.

Section 11 of the Sri Lankan labelling regulations is relevant to the recommendations of professionals. Section 12 states that no label or advertisement relating to any food shall contain a statement or claim that such food has special characteristics unless approval is granted by the Chief Food Authority. The meaning or interpretation of the term 'claim' is stated only in section 13.3. Provisions of claims in the Regulations do not automatically extend to section 11 and 12 of the Regulations as the term 'claim' is restricted to section 13. Therefore, that meaning or interpretation of claim does not refer to the entirety of the Regulations (including section 11 and 12), but only to section 13.

The term 'claim' also been stated in section 12 of the Sri Lankan labelling regulations as an analogue to the term 'statement' but without an interpretation. Here the term 'claim' should be interpreted in general; therefore, it cannot have the same meaning of the claim as described in section 13.3. The term 'special characteristics' is not defined or explained. The term 'special characteristics' is not included in the definition of the term 'claim' in section 13.3 and the meaning of the term 'claim' in section 13.3 does not refer to section 12 either. It 
should be noted that these descriptions covered under section 11 and 12 are separate to 'claims' that are defined in section 13.3.

Approval of the Chief Food Authority of Sri Lanka is required only for descriptions covered by section 11 and 12. In other words, it could be interpreted as a 'claim' that does not require the approval of Chief Food Authority as section 11 and 12 do not come under the purview of claims stipulated in section 13.

\section{Types of Claims}

The Regulations do not expressly classify claims even though specific types of claims are stated and defined. For example, nutritional claims are specifically identified in the schedule V. Nutritional claim is further split in schedule $\mathrm{V}$ to nutrient content claims, comparative claims and nutrient function claims.

Schedule V defines a nutrient content claim as a nutrition claim that describes the level of a nutrient content in a food (such as "source of calcium", "high in fibre", "low in fat"). In addition, section 13.7.vi stipulates terms 'fortified' and 'enriched' which are also nutrition content claims. A comparative claim is defined as a claim that compares the nutrient levels or energy value of two or more foods (such as "reduced", "less than", fewer", "increased", "more than" in relation to other products). Nutrient function claims describe the physiological role of the nutrient in growth, development and normal functions of the body (such as "Calcium aids the development of strong bones and teeth", "Protein helps build and repair body tissues", "Iron is a factory for red blood cell formation", "Vitamin E protects fat in body tissues from oxidation", "Folic acids attributes to the normal growth of the foetus").

The Regulations do not stipulate the term 'health claim'. However, schedule V (d) (IV) provides certain limitations on health-related claims, stating "the claim shall not imply or include any statement to the effect that the nutrient would afford a cure or a treatment for or protection from, any diseases".

Claims related to non-nutritional properties are not expressly termed or classified. However, claims related to non-nutritional properties such as 'pure', 'natural' and 'substitute' are specifically stated in section 13(4), 13(5) and 13(6) respectively. 
Both Codex and FSANZ classifies 'claims related to nutritional properties' as nutrition and health claims; whereas, there is no such explicit classification in the Sri Lankan law. Codex has excluded ingredient list and nutritional information from nutrition claims probably because they are regulated by specific legal provisions or standards. Therefore, restrictions relevant to claims do not apply to the ingredient list and nutritional information according to the Codex. Sri Lankan labelling regulations neither categorize claims related to nutritional properties nor defines nutrition claims. The term 'health claim' is also not mentioned in the Regulations. Sub-categorization of nutrition claim in Sri Lanka is not consistent with Codex standards: nutrition function claim is a nutrition claim in the Regulations whereas it is a health claim in Codex as well as in FSANZ. The Regulations also failed to identify non-addition claims (for example, 'no added sugar' and 'no added salt'). In addition, the Regulation when compared with Codex also failed to identify and regulate claims such as "fresh", "homemade", "organically grown" and "biologically grown".

\section{Regulation of Claims}

Certain claims in the Regulations are absolutely prohibited, some are relatively prohibited while other claims are considered mandatory to display on labels.

Absolutely prohibited claims include: any false claim; claims stating "dietary fats are a protection against heart diseases or of benefit to persons suffering from heart disease"; claims of "tonic, restorative or medicinal properties"; claims of "beneficial, cure, alleviate or prevent any illnesses" (either directly or indirectly); and claims on statements of weight loss (e.g., "aid for slimming, weight control or weight reduction)".

Relatively prohibited claims are nutrient content claims which are not in accordance with table A of schedule v. Further, and the terms 'pure', 'natural' and 'substitute' or any words implying them are prohibited unless specified conditions stated in provisions of section 13 are satisfied.

Other claims such as 'country of origin' for imported products, 'ingredients' and 'colour codes' are claims that should be mandatorily displayed on labels. 
Sri Lankan regulations are apparently more stringent in claims relevant to health concerns. Even though Sri Lankan regulations do not generally identify health claims as a category, specific health related claims such as "dietary fats are a protection against heart diseases or of benefit to persons suffering from heart disease"; "contains tonic, restorative or medicinal properties"; "cures, alleviates or prevents any illness"; and "aids slimming, weight control or weight reduction" are absolutely prohibited (Government Publication Bureau, 2011). Certain health claims are allowed under conditions in the codex standards. However, as the Regulations prohibit specific health claims, it indirectly implies that other health claims are allowed in Sri Lanka without restrictions. This is a result of failing to identify health claims as a separate entity by the Sri Lankan regulations. FSANZ has simply but effectively regulated health claims by prohibiting the use of therapeutic claims and any claims in infant formula (FRL, 2020) which seems to be a broader restriction than those practiced in Sri Lanka.

No claims are explicitly permitted without any restrictions by the Sri Lankan labelling regulations, while FSANZ has specifically permitted claims on food that is intended for further processing, packaging or labelling prior to retail sale, and food that is delivered to a vulnerable person by a meal delivering organization (FRL, 2020). Further FSANZ allows any claims about the risks or dangers of alcohol consumption or about moderating alcohol intake and permitted Health Star Rating symbols (FRL, 2020). Even though there are no explicitly permitted claims stipulated in the Regulations, claims related to non-nutritional properties (except for words 'pure', 'natural', and 'substitute' or words implying them) and health claims (except for specifically stipulated health claims) are allowed as there are no restriction to stop them.

Apart from food labelling regulations there are other laws in Sri Lankan jurisdiction which regulate claims. Although not explicitly implied as claims, some consumer law provisions also exist to protect against misleading claims. The Sri Lankan Consumer Affairs Authority Act of 2003 stipulates the term 'representation' instead of 'claim' and false representations are been prohibited by the section 31 of the Act. Specific types of false representations have been stipulated to make it clearer (Government Publication Bureau, 2003). However, clear descriptions are not present under food labelling regulations. 


\section{Conclusions}

Sri Lankan labelling regulations on claims are overly complex and potentially misleading. The term 'Special characteristics' mentioned in section 12 of the Sri Lankan labelling regulations need to be more explicitly elaborated in order to gain a practical validity. The scope of the section 11,12 and 13 of the labelling regulations should clearly clarify the issue with simple instructions and examples. In addition, specifying permitted claims (without restrictions) also will improve the compliance by food industry and to improve the enforcement of current laws by Authorized Officers.

The Sri Lankan food labelling regulations have largely failed to adopt the standard definitions and classification of Codex Alimentarius on labelling claims, or develop another reasonable classification that comprehensively identifies and addresses all standard types of claims. Scientific classification should be adopted when making future amendments.

Legal provisions on food labelling claims in Sri Lanka are not adequate when compared to Codex and legal standards in other developed countries such as Australia, which results in Sri Lankan consumers receiving lower standards of health protection than citizens of other countries.

\section{Abbreviations}

FSANZ - Food Standards Australia and New Zeeland

FRL - Federal Register of Legislation

\section{Acknowledgements}

Authors sincerely appreciate the academic and non-academic staff of the Department of Public Health, Faculty of Health, University of Technology Sydney, Australia for their valuable assistance.

Authors pay gratitude to the Post Graduate Institute of Medicine, University of Colombo and Ministry of Health Sri Lanka for their support. 


\section{References}

Arellano, B., Bernstein, J., Norsen, S., Schermel, A., \& Abbe, M. (2017). Assessing nutrition and other claims on food labels: a repeated cross-sectional analysis of the Canadian food supply. BMC Nutrition, 3 (74). https:// bmcnutr.biomedcentral.com

Cambridge Dictionary. (2020). Claim.

https://dictionary.cambridge.org

Codex Alimentarius. (2020). Codex general standard for the labelling of pre-packaged foods, 1-1985, Rev. 1991. http://www.fao.org/3/Y2770E/y2770e02.htm

Codex Alimentarius. (2020). Codex guidelines on nutrition labelling, 2-1985, Rev. 2017.

http://www.fao.org/fao-who-codexalimentarius

Collings Dictionary. (2020). Claim. https://www.collinsdictionary.com

Federal Register of Legislation. (2020). Food Standard Code. https://www.legislation.gov.au

Food Standards Australia and New ZeeLand. (2006). The effect of a disclaimer on consumer interpretation of the 'no added sugar' claim, Technical report: consumer research on 'no added sugar' claims. https://www.foodstandards.gov.au

Food Standards Australia and New ZeeLand. (2007). Consumer Use of Nutrition Content Claims in Shopping Environments, Research Report. Colmar Brunton Social Research.

https://www.foodstandards.gov.au

Food Standards Australia and New ZeeLand. (2019). Consumer Attitude Survey 2007. TNS Social Research. https://www.foodstandards.gov.au

Government Publication Bureau. (2003). Consumer Affairs Authority Act of 2003. Government Press, Sri Lanka.

Government Publication Bureau. (2005). Food (Labelling and Advertising) Regulations of 2005. Government Press, Sri Lanka.

Gunnars, K. (2016). Top 11 biggest lies of the food industry. Authority Nutrition. https://authoritynutrition.com 
Hettiarachchi, C. A. (2017). Compliance of labels of beverages to the food labelling regulation and effectiveness of an advocacy package in improving adherence to labelling regulations by food industry. Doctorate theses, Post Graduate Institute of Medicine, University of Colombo.

Jolliffee, T. (2013). The loopholes of food labelling. Spark people. https:// www.sparkpeople.com

LaBarbera, M. (2012). Reading food labels-how does it help buy healthier foods? Nourish interactive. https:// www. nourishinteractive.com

Prathiraja, P. H. K., \& Ariyawardana, A. (2011). Impact of Nutritional Labelling on Consumer Buying Behavior. Sri Lankan Journal of Agricultural Economics, 5,35-46.

https://doi.org/10.4038/sjae.v5i0.3475

Roe, B., Levy, A. S., \& Derby, B.M. (1999). The Impact of Health Claims on Consumer Search and Product Evaluation Outcomes: Results from FDA Experimental Data. Journal of Public Policy \& Marketing, 18(1):89-105.

https://doi.org/10.1177/074391569901800110

Talagala, I.A., \& Arambepola, C. (2016). Use of food labels by adolescents to make healthier choices on snacks: A crosssectional study from Sri Lanka. BMC Public Health, 16:739. https://doi:10.1186/s12889-016-3422-1 